\title{
The Feasibility of Applying PBL Teaching Method to Surgery Teaching of Chinese Medicine
}

\author{
Qianli Tang \\ Guangxi University of Chinese Medicine \\ Nanning 530001, China \\ Tel: 86-771-3941-063Ｅ-mail: htmgx@163.com
}

Yuan Yu, Qiuyan Jiang, Li Zhang, Qingjian Wang \& Mingwei Huang

The No.1 Hospital of Guangxi Traditional Chinese Medical University

Nanning 530023, China

Tel: 86-771-5848-511 E-mail: taijiyu81@163.com

This research is supported by the fund of Project of China National Planning of Education (No. FIB060367) and Project of Teaching Reform of Higher Education of Guangxi in the New Century (No. 2006B57), 2006

\begin{abstract}
The traditional classroom teaching mode is based on the content of the subject, takes the teacher as the center and gives priority to classroom instruction. While PBL (Problem Based Learning) teaching method breaches the traditional mode, combining the basic science with clinical practice and covering the process from discussion to self-study to re-discussion and re-self-study, and students become into the active role of learning under this teaching method,. This research finds that PBL teaching method is welcomed and accepted by most of the students and teachers, and it will improve the abilities such as understanding, comprehensive analysis, diagnostic identification and treatment application. It is feasible to apply PBL method in teaching surgery of Chinese medicine.
\end{abstract}

Keywords: PBL teaching method, Surgery of Chinese medicine, Feasibility study

\section{The definition of PBL}

PBL (Problem Based Learning) is a kind of teaching method in medical science taking the students as the active role and giving priority to integration of basic science and clinical practice (Huang, 2002, p.69-70). This teaching method accords with the characteristics of medical science, emphasizing that the theory should be organically combined with clinical practice and closely correlated to the practical problems. The principle of PBL teaching method is to discuss the problems in groups, take the case history as the lead, problems as the base, students as the main body and teachers as orientation. Every problem is carefully designed, and the contents that should be grasped in the teaching object are exactly arranged in these problems (Ma, 2004, p.71-75).

\section{The reasons for implementing PBL teaching method}

At present, most Chinese medical colleges and universities are still implementing traditional teaching mode. Under this mode, before their clinical practice, the students have systematically and extensively studied the basic and clinical courses in a limited period with a complete knowledge structure under the well arranged course plan. But the surgery of Chinese medicine is based on clinical practice with comprehensive and profound contents, and disadvantages are obvious to adopt the traditional teaching mode. To the contrast, PBL teaching method is a sort of advanced teaching method consistent with the educational objective of quality education advocated in China. The advantages of PBL teaching method can be summarized as that (1) emphasizing the cultivation of students' learning abilities through searching for their wanted information source so as to train their lifelong learning skills;(2) fully exerting students' learning enthusiasms, and encouraging their study on demand ; (3) helping the students to solve the clinical problems and training their self-study skills; (4) strengthening the involvement of various subjects, avoiding unnecessary 
repetitions and helping the students to integrate the crossed contents of different subjects; (5) strengthening the relationships among teachers and students and cultivating students' abilities of interpersonal communication and cooperation.

\section{Research objective}

This research adopts questionnaire investigation to evaluate the PBL teaching method and the traditional teaching mode. A certain amount of students were randomly divided into two groups, respectively implementing different teaching modes to evaluate the teaching quality of the two groups. After the implement, the questionnaire investigation was conducted among the teacher and students to evaluate the PBL teaching mode and the traditional teaching mode. This research explores the new teaching mode in order to provide a fresh view and way to the reform of traditional teaching of surgery of Chinese medicine.

\section{Research method}

This research adopts questionnaire investigation to evaluate the PBL teaching method and the traditional teaching mode. A certain amount of students were randomly divided into two groups, respectively implementing different teaching modes to evaluate the teaching quality of the two groups. After the implement, the questionnaire investigation was conducted among the teacher and students to evaluate the PBL teaching mode and the traditional teaching mode.

\subsection{Questionnaire Investigation}

\subsubsection{Design of questionnaire}

The self-filled questionnaires are adopted, and the questionnaires are divided into two sorts, i.e. questionnaire for teachers and questionnaire for students and every sort of questionnaire includes two sorts of question, i.e. close questions and open questions. All questionnaires are answered anonymously to respect individual privacy.

The first part of questionnaire for students is about the attitudes that students feel the teaching method adopted by the teacher in Guangxi University of Chinese Medicine. After the learning for a certain time, aiming at the problems that whether the teachers had encouraged the students to actively take part in the classroom and whether teacher had adopted the traditional stuffing method of teaching, students are required to give correct options which are divided into three sorts including agreement, neutrality and disagreement.

The second part of questionnaire for students is about the satisfaction status that students feel the teaching method adopted by the teacher in Guangxi University of Chinese Medicine. In order to know whether the teacher has flexibly exerted teaching method, whether the teacher has applied the PBL teaching method, whether the teacher has paid attention to the communication with students, whether the teacher has given instructions for students in the learning method in the teaching process, whether students are satisfactory with these aspects. Students are required to answer how many teachers had achieved the above requirements, and the options are divided into five classes, and if students think $100 \%$ of the teachers have flexibly applied the teaching method, they can choose "all"; and if they think only $75 \%$ of the teachers have achieved this requirement, they can choose "most". According to this rule, for $50 \%$, they can choose "half", for $25 \%$, they can choose "a little", and for $0 \%$, they can choose "none".

The first part of questionnaire for teachers is about the teachers' knowledge source of PBL, understanding of PBL, the feasibility of PBL in Guangxi University of Chinese Medicine, and if PBL is introduced, what is the attitude of the teachers so as to forward practical suggestions for the policy makers. Aiming at the hesitations of the teachers to try out PBL, the university may put forward the solution one by one and clean the obstacles for the introduction of PBL. Therefore, two close questions and one open question are set up in the questionnaire for teachers. To investigate the source of PBL knowledge, the questionnaire sets up one question which divides the source into four sorts, i.e. foreign literature (known in foreign materials), domestic literature (known in domestic materials), other media(through broadcast, TV, newspaper or verbal transfer), and no knowledge of PBL.

The second part of questionnaire for teachers is about the teachers' attitudes for the introduction of PBL teaching method in Guangxi University of Chinese Medicine. To know the teachers' attitudes towards the introduction of PBL, the questionnaire sets up four options, i.e. "completely agree", "partially agree", "no comments" and "disagree".

\subsubsection{Investigation objects}

The objects of the investigation are part of the teachers (the sum of 86) and students (the sum of 1477) in the campus and hospitals of Guangxi University of Chinese Medicine. The teachers include the teachers who engage the teaching working at the campus and hospitals of the university, and the students include the students of all orbits (a five-year full time system) who have received education of basic medical science.

\subsubsection{Sampling method}

Sampling of the students is randomly taken from the students' muster roll in the educational administration department of the university, and the questionnaires are delivered and collected by the teachers. Sampling for the teachers is 
randomly taken according to their different technical titles.

\subsection{Method of evaluating the education quality}

\subsubsection{Objects and method}

The sample objects are 112 undergraduates from Grade 2003 in the university with 64 undergraduates in the first class and 48 in the second class. The second class is taken as the experiment group, and the first class as the control group.

\subsubsection{Research method}

\section{(1) Course and period}

The period of the two groups are respectively 54 academic hours according the requirements listed in the outline and plan of teaching, and the course for surgery of Chinese medicine is started in the sixth semester.

(2) Teaching method

For the control group, the traditional teaching method was adopted, using the common teaching facilities such as multimedia, classroom lecturing, and summarization before the end of lecture.

For the experiment group, the following concrete methods were adopted:

The first one, before the lecture of every chapter questions are designed and delivered to the students, and the students prepare the lecture by self-study. The questions should be carefully designed in a proper sequence in view of the students' level so as to cultivate the students' ability of self-study.

The second one, according to the contents of lecture, the teacher utilizes part of the time to question the individual student, and part of the time for group discussion so as to fully exert the students' enthusiasms and creation. Students are encouraged to put forward their own opinions, and the teacher only instructs these opinions to ensure the intention of "putting forward questions- considering problems-solving problems".

The third one, the teachers' questions should be based on the most important and difficult points. At the class the teacher may omit repetitive contents and only target the key contents so as to help the students to understand and memorize the knowledge.

\section{(3) Evaluation of education quality}

An examination is required for the two groups, and the examination room, time and invigilation are arranged by the educational administration department.

The test papers are made from the bank of test papers with additional contents of the teachers' requirements. The objective questions (multiple choices cloze, judgment and concept definition) cover $60 \%$, to check the students' understanding of the basic concepts and theories of the surgery. The subjective questions (answering questions, demonstration, and case analysis) cover $40 \%$ to test the students' abilities of understanding, comprehensive analysis, diagnostic identification and treatment application. The test papers and answer sheets are forwarded to the educational administration department

After the examination, the educational administration department and the relative personnel seal the names of the test papers and deliver them to the paper reading teachers, the teachers read the papers in turns and figure out the scores. Above 90 scores is regarded as excellent, 80-89 scores as good, 60-79 scores as passed, and less than 60 as failed.

(4) Statistical disposal

All the data are disposed by the SPSS11.0 software according to the statistics, and the data of questionnaire investigation adopts the descriptive statistic, and the teaching quality evaluation adopts wilcoxon order and test, and $P<0.05$ means the difference is significant.

\section{Research result}

\subsection{The result of questionnaire investigation}

In the questionnaire that whether the teacher had encouraged the students to actively take part in the classroom teaching and whether teacher had adopted the traditional stuffing teaching method, $74.88 \%$ of the students thought the present teaching is the stuffing teaching. When evaluating the teachers' teaching methods, only $30.13 \%$ of the students thought that about $50 \%$ of the teachers had adopted the appropriate teaching method. In the questionnaire aiming at teachers, $31.40 \%$ of teachers didn't know the PBL teaching method, but $77.91 \%$ of teachers agreed the advantages of this teaching method.

\subsection{The evaluation of education quality}

After comparing PBL teaching mode with traditional teaching mode, we can find the students who accept the PBL teaching mode are better than the students in the traditional mode group for the achievements of subjective questions 
about understanding, comprehensive analysis, diagnostic identification and treatment application $(P<0.01$, seen in Table $1)$. But for the achievements of objective questions, both groups has no obvious difference $(P>0.05$, seen in Table 2$)$.

\section{Conclusions}

Most of the students and teachers would like to accept and adopt PBL teaching mode, which enjoys the advantages of promoting students abilities such as understanding, comprehensive analysis and diagnostic identification and treatment application., increasing students' learning interests, strengthening students' learning enthusiasm, developing the space of combining basic theory with clinical practice, deepening students' understanding to theoretical knowledge, cultivating students' creation, and promoting the establishment of lifelong learning method. The method of inducement, self-innovation and self-learning adopted by the PBL teaching method can effectively avoid the phenomena that student depend on teachers' instruction too much, and foster a sort of spirit of innovation, promote the complete communication between teachers and students, and fully inspire students' self learning enthusiasms. It is to implement practical study from the view to cultivate excellent doctors, i.e. the learning is to fulfill the necessary medical knowledge and human science knowledge such as doctor-patient relationship, medical-social relationship and doctor-nurse cooperation for the practical clinical work (Hodgson, 2001, p.546-547). At the same time, PBL teaching method will encourage the students to find out the difficult and doubtful points, and to solve the problems, develop the students' skills of literature searches and consultation, and cultivate their abilities of concluding, summarizing and logical reasoning.

The surgery of Chinese medicine is a science with strong practice, and it possesses not only higher requirements for the theoretic knowledge, but also strong practical ability. When the PBL teaching method is applied in the teaching of surgery of Chinese medicine, it will certainly exert the function to cultivate talents more quickly and effectively. So the application of PBL teaching method in the surgery teaching of Chinese medicine is feasible.

\section{References}

Hodgson C S, Baillie S \& Contini J. (2001). Creating Web-based Patient Education to Enhance Students' Experience in a PBL Curriculum. Acad Med. No.76(5). p.546-547.

Huang, Suxia \& Yufang. (2002). PBL Teaching Mode and Medical Student Quality Cultivation. China Higher Education Research. No.9. p.69-70.

Ma, Hongliang. (2004). The Quasi-experiment Research and Thinking about Problem-based Learning among the Undergraduates. Modern Educational Technology. No.14(1). p.71-75.

Table 1. Exam achievements comparison between two groups of student for subjective problems

\begin{tabular}{|l|l|l|l|l|l|}
\hline & no. of students & excellent & good & passed & failed \\
\hline Comparison group & 64 & 12 & 42 & 9 & 1 \\
\hline Experiment group & 48 & 21 & 24 & 3 & 0 \\
\hline
\end{tabular}

Note: $Z=2.968, P<0.01$.

Table 2. Exam achievements comparison between two groups of student for objective problems

\begin{tabular}{|l|l|l|l|l|l|}
\hline & No. of students & excellent & good & passed & failed \\
\hline Comparison group & 64 & 14 & 44 & 6 & 0 \\
\hline Experiment group & 48 & 10 & 33 & 5 & 0 \\
\hline
\end{tabular}

Note: $Z=0.195, P>0.05$. 